\title{
UMA LITERATURA GLOBALIZADA: O CORPO LITERÁRIO DE FAVELOST, DE FAUSTO FAWCETT
}

\author{
Robson Batista dos Santos Hasmann* \\ Instituto Federal de São Paulo / Universidade de São Paulo
}

\begin{abstract}
Resumo: Ao analisarmos a relação da literatura com a tecnologia, percebemos que, se no nível temático há uma tendência a uma representação negativa dos avanços tecnológicos, no nível estrutural e estético, porém, o certo é que houve vários avanços, haja vista a cyberfiction. No Brasil, país em que tradicionalmente a literatura esteve marcada pela denúncia social, a entrada na pós-modernidade, com seus processos de globalização e de aprimoramento tecnológico, algumas modificações começam a operar nos dois níveis. Para verificar essas transformações, o trabalho discute alguns aspectos do romance Favelost (the book), de Fausto Fawcett. Aproximando-se da ciberficção, a obra destaca-se pelo uso recursos de linguísticos como o neologismo, a ironia, o trocadilho, jogos de palavras etc. A exploração da linguagem, assim, torna-se uma espécie de revitalização da literatura sem a preocupação quase realística que tem sido uma das principais marcas da literatura brasileira contemporânea. Sob as leituras do filósofo Pelbart (2013) do niilismo nietzschiano, a profusão de signos que se inscrevem no corpo da narrativa pode ser uma amostra de um resgate daquilo que é marca mais profunda do humano e da literatura: a representação simbólica.
\end{abstract}

Palavras-chave: Literatura brasileira contemporânea. Inovação e tradição. Pós-humano. Niilismo.

\section{Introdução}

Os discursos perpassam o sujeito: essa constatação de que somos constituídos pela linguagem e que está discutida por diversas áreas do saber como a Psicanálise e a Filosofia emerge intensamente na literatura contemporânea. Emergência que se deve, claro, à sua força de captar os temas e os sentimentos que circulam no presente e que a reflexão cartesiano-

\section{(1)(9)}

BY NC ND Esta obra está licenciada sob uma Licença Creative Commons.

\footnotetext{
* É licenciado em Letras Português / Espanhol - Faculdades Integradas Teresa D`Ávila (2002). Pela Universidade de Taubaté (UNITAU) especializou-se em Literatura (2004) e em Leitura e produção de texto (2009). Em 2010, especializou-se em Espanhol Língua Estrangeira: Metodologia de Ensino de Espanhol, pela Universidade de Brasília (UnB). É mestre em Letras pelo programa de Língua Espanhola e Literaturas Espanhola e Hispano-Americana da Universidade de São Paulo (2013), programa em que realiza estudos de doutoramento. É professor de Espanhol do Instituto Federal, campus São João da Boa Vista. E-mail: robsonhasmann@ig.com.br.
} 
iluminista nem sempre consegue classificar e explicar sem certo distanciamento histórico. Prova disso são as categorias de autoficção e testemunho, bem como o ressurgimento das memórias.

Por outro lado, nessa dimensão satélica a literatura herdou dos modernos (Flaubert e Baudelaire para ficar nos exemplos óbvios) a capacidade de refletir-se e refletir sobre si. É justamente neste ponto que ela, cuja constituição sempre foi a linguagem, ganha força a partir da descoberta/constatação de que é, assim como outros sujeitos, também discurso; e é também um corpo. Como, então, existir frente a outros sujeitos que são, da mesma forma, compostos de linguagem?, eis uma questão que levantamos acerca da literatura.

Talvez a resposta seja uma "escritua por vir" ou "desastrosa". O certo, porém, é que ela ainda não existe, mas seus vestígios já estão presentes na contemporaneidade. Dessa forma, ao tentar compreender as configurações do mundo a partir de um dos temas mais instigantes na atualidade, possamos acender uma luz na bifurcação dos caminhos do discurso literário. Trata-se da temática do corpo.

Sendo também um corpo no mundo contemporâneo, a literatura pode estar sujeita aos apelos, às mutilações, aos excessos, ou, nas palavras de Agamben, ao desnudamento, semelhantemente ao que ocorre com as imagens "mercadocelebratoriais" das TVs e outdoors? Essa questão evoca outras, ou seja, na confluência aparece a dispersão: o desnudamento do literário recupera um naturalismo esgotado e em muitos sentidos vazio de literatura porque pleno de real, tal como aconteceu a muita literatura no século 19? Ou o desnudamento conduz ao silêncio, que, materializado, implode a linguagem e, consequentemente, a literatura?

Neste trabalho pretendemos discutir esses questionamentos a partir de algumas narrativas brasileiras produzidas durante as primeiras décadas do século 21 , com atenção particular a Favelost, de Fausto Fawcett.

\section{Pós-ismos, pré-alguma coisa?}

Já nas duas últimas décadas do século 20, diversos estudos mostraram (ou anunciavam) o desaparecimento da modernidade e o surgimento de um período pós-moderno. Um deles, hoje já um clássico sobre esse período, é Pós-modernismo: a lógica cultural do capitalismo tardio (2004), de Fredric Jameson, cuja primeira edição é de 1991. Na "Introdução", o autor anuncia a principal diferença entre os períodos: se para os modernos o futuro era algo a se alcançar e construir, os pós-modernos buscam eventos, não mais mundos novos. Além disso, há no pós-moderno a constatação de que "os conteúdos são somente outras imagens" (JAMESON, 2004, p. 13). 
Nesse sentido, as manifestações artísticas pós-modernas caracterizam-se pelo

apagamento [...] da antiga fronteira entre a alta cultura e a assim chamada cultura de massa ou comercial, e o aparecimento de novos tipos de texto impregnados das formas, categorias e conteúdos da mesma indústria cultural que tinha sido denunciada com tanta veemência por todos os ideólogos do moderno, de Leavis ao New Criticism americano até Adorno e a Escola de Frankfurt. (JAMESON, 2004, p. 28).

De maneira geral, a era pós-moderna colocou no centro do debate acadêmico as implicações dos avanços da alta tecnologia e suas relações em favor ou detrimento do ser humano. As máquinas, interligadas por uma infinita rede de computadores, criaram nas primeiras décadas do século 21 um estilo de vida estreita e estritamente ligada aos recursos de mídia eletrônica. Essas modificações impactaram os mais diferentes âmbitos da sociedade. $\mathrm{Na}$ política, na economia e nas artes, os recursos oferecidos por essas tecnologias configuraram um mundo que, apesar de manter muito das tradicionais formas de organização dos estados, tem promovido uma horizontalização das diversas esferas sociais.

No âmbito artístico, mais especificamente na literatura, muito dos recursos estão sendo aproveitados para enriquecer as formas de produção e de representação. Se o cinema provocou uma guinada na forma de trabalhar a linguagem tanto na prosa quanto na poesia, os recursos atuais levam ao extremo as oportunidades, de tal modo que já existe, por exemplo, uma "literatura eletrônica", em que a palavra, a imagem e o som, suportados por instrumentais transmidiáticos (softwares de edição, internet, plataformas virtuais etc.), são amplamente utilizados a ponto de, inclusive, criar novas formas de experiência de leitura ${ }^{2}$.

Nesse contexto, ao tentar explicar as modificações, é inevitável não recorrer a uma "tradição" do relacionamento entre literatura e tecnologia; relação repleta de tensões, em que há ora uma exaltação dos poderes da máquina ora atitudes de medo, desconfiança, angústia e oposição.

A modernidade, que alguns historiadores situam no Renascimento, pode ser considerada o período em que se ampliaram as discussões sobre a relação literatura e tecnologia. Nesse contexto, certamente a epopeia camoniana Os lusíadas é um grande exemplo. No episódio conhecimento como "A máquina do mundo", estaria um dos primeiros vestígios do quanto as transformações nos processos de organização social estavam

\footnotetext{
${ }^{1}$ Inserir aqui algumas ideias de Literatura eletrônica (2009), de Katherine Hayles.

${ }^{2}$ Recursos como a desmontagem e consequente possibilidade de fazer leituras não lineares, o uso de imagens para compor a narrativa, a intertextualidade, a produção coletiva etc. são amplamente utilizados por esse tipo de literatura. Algo, porém, sem novidade a não ser pela mediação.
} 
impactando a arte. Mesmo sem utilizar os recursos disponíveis pela incipiente tecnologização para modificar sua obra, Camões sinaliza o quanto aquilo seria um grande tema.

Durante o Iluminismo, outro período a que se atribui o início de uma sociedade marcada pelos processos de racionalização dos meios de produção técnica, o romance Frankenstein, de Mary Shelley, recoloca a tensão entre homem e ciência e marca os pontos negativos dessa evolução.

Na segunda metade do século 19, surgem os chamados romances de ficção científica. A principal marca desse gênero é a capacidade imaginativa para criar mundos futurísticos nos quais a aplicação da ciência, isto é, a tecnologia organiza as relações humanas. Seja provocando o deleite da imaginação seja possibilitando hipóteses sobre a real concretização do mundo imaginado, a ficção científica passou para uma das mais importantes invenções do século 19 , o cinema.

Ao colocar a imagem em movimento, o cinema transforma definitivamente a linguagem literária. Somado ao telégrafo, à máquina a vapor, à linguagem jornalística, o cinema rompe as estruturas sintáticas tradicionais e as longas descrições tipicamente utilizadas pelos autores de cunho realista.

Nesse processo de contato entre a linguagem literária e as tecnologias, o século 20, em que a exaltação da máquina, da tecnologia, sobretudo dos recursos midiáticos estão definitivamente inseridos em todas as esferas e status sociais e fazem parte da conformação do trabalho, do lazer, da pesquisa acadêmica, dos processos de produção industrial e do comércio, como acontece essa relação? Que formas podem ter tomado a angústia de Vasco da Gama e de Victor Frankenstein; o medo do admirável mundo novo e o voyerismo de 1984 na literatura brasileira contemporânea?

\section{Globalização e "pós-modernização"}

O geógrafo David Harvey, autor de um dos primeiros estudos significativos sobre a pós-modernidade com o livro Condição pós-moderna ${ }^{3}$, sintetizou o que seria o modernismo: uma perturbadora e fugidia estética a condições de modernidade produzidas por um processo particular de modernizações. (HARVEY, 2003). Certamente, os processos de modernização, baseados sobretudo no modelo fordista de produção, plasmaram um modo de desenvolvimento capitalista que, não obstante a busca pela homogeneização em todas as partes do globo, deixou marcas diferentes naqueles países chamados de terceiro mundo.

\footnotetext{
${ }^{3}$ A primeira edição é de 1989.
} 
Nas interpretações sobre a América Latina, por exemplo, é comum ouvir-se falar que a literatura possui um exuberante modernismo em uma modernização precária. A questão colocada pelas ciências sociais é que no processo de modernização, países como Brasil não chegaram a desenvolver-se plenamente até a década de 80 . Acontece, porém, que é a partir dessa década em que pesquisadores das diversas áreas das humanidades questionam a mudança em um terceiro estágio do capitalismo.

É nesse sentido, então, que Harvey, geógrafo atento às configurações planetárias a partir das modificações nos processos de produção em seu modelo fordista detecta já na década de 80 a guinada que o mundo sofreria com o advento, no século 21 , das tecnologias de comunicação e produção do conhecimento. A acumulação do capital por meio da fabricação de bens e a expansão de empresas "filiais" cedeu espaço (ou foi substituída) pela acumulação flexível de bens imateriais. Trata-se agora de uma profusão de signos gerada por e geradora de um infocapitalismo, conforme expressão utilizada pelo filósofo italiano Federido Berardi, o Bifo, em After the future (2011).

Dentre as diversas consequências decorrentes desse processo, destaca-se a experimentação do tempo. Se no modelo fordista o valor do trabalho estava relacionado ao tempo de produção do bem material, no mundo contemporâneo a geração de um "produto", isto é, um conhecimento, uma informação etc. é difícil de ser medida, uma vez que é algo abstrato, imaterial.

Ao mesmo tempo, as empresas antes especializadas em partes do processo total de produção, convivem agora com empresas receptoras e distribuidoras de conhecimento, as chamadas data center. Nessas empresas, o acúmulo de tecnologia, ou seja, o maquinário é muito alto, mas ao contrário do que acontecia quando "filiais" em se instalavam em países periféricos e, apesar do barateamento da mão-de-obra, construíam uma cadeia de serviços e empregos indiretos, os data center quase não expandem o trabalho. ${ }^{4}$

A rede comunicativa e informacional mediada por computadores permitiu realizar um dos mais fortes desejos da modernidade: a expansão do mundo e dos bens para todos os lugares e, de certa maneira, democratizar o acesso à informação. Decorrente disso a troca de informações e a facilidade de obter conhecimento encurtou distâncias e o tempo. O futuro, perspectiva da modernidade, cedeu espaço para um aperspectivismo em que os tempos confluem para um constante agora.

\footnotetext{
${ }^{4}$ Seria de grande valia fazer uma análise sociológica da relação trabalhista nesse novo modelo capitalista. Nosso propósito, aqui, porém, não chega a tanto.
} 
Essas "conquistas" desse avançado estágio do capitalismo estão acompanhadas e só foram possíveis pelos avanços tecnológicos, ou mais exatamente, pela aplicação das ciências no desenvolvimento de produtos artificiais que fazem a intermediação entre o trabalho e seu produto final.

Nesse cenário contemporâneo, isto é, no estágio avançado do capitalismo, globalizado e altamente tecnológico, as conformações políticas e sociais ganham também são modificadas. Sob a perspectiva política, o principal ponto de discussão é as maneiras de exercícios do poder, enquanto para o social a problemática da organização urbana e a criação de periferias dentro das periferias está enfatizada.

\section{Pós-humano e niilismo}

O poder político atual, quer o da política de Estado quer o das empresas privadas, está direcionado ao controle do corpo. Nesse sentido, o mundo moderno, que deseja libertarse das restrições medievais, em que havia o controle dos desejos e dos impulsos, agora incentiva a liberação total do corpo, o uso de psicotrópicos, próteses, substâncias químicas capazes de potencializar os músculos etc. A esses instrumentais, devem ser acrescentados o incentivo para a produção e aquisição de aparelhos tecnológicos (celulares, tablets, computadores, Iphones, Ipads etc.), cuja dependência se torna cada vez maior e símbolo da possibilidade de uma melhora das condições de vida social.

Esse controle do corpo do indivíduo toma dimensões gigantescas quando ele é dirigido ao corpo social. O resultado são configurações urbanas opressoras: inchaço da população. Diferentemente do alto modernismo, em que ocorria o êxodo rural, a explosão demográfica da pós-modernidade é um mal autóctone, acentuada pela conurbação de cidades que estão ao redor das metrópoles. Nessas cidades, o cenário é fluído, mutante, quer dizer, transforma-se a todo instante. Além disso, novas regras sociais precisam ser criadas frequentemente, pois as conformações escapam às lógicas conhecidas.

Atuando no corpo, o estágio avançado do capitalismo abre um dos caminhos mais complexos de reflexão na pós-modernidade: a ligação extrema do ser humano com a máquina, de tal maneira que há muito cogita-se a existência de um ser pós-humano. Durante a modernidade, era clara a proposta de que toda a técnica estava direcionada a melhorar o homem. O contexto atual, porém, parece levar às últimas consequências a proposta nietzschiana não de uma melhora do humano, mas uma superação.

Essa superação significa um o desaparecimento dos limites entre orgânico/artificial e real/virtual, cujos resultados conduzem a uma sensação de niilismo. Para compreender melhor 
as causas dessa sensação, pode contribuir a leitura que Peter Pál Pelbart (2013) faz do termo. Propondo uma genealogia desde seu surgimento até as interpretações dadas pelas leituras de Nietzsche, o filósofo brasileiro constata que no processo de dessubjetivação do sujeito pósmoderno, o vínculo estreito com a máquina está na capacidade de o capitalismo provocar o esvaziamento da identidade por meio de "signos a-significantes": na servidão maquínica somos tratados "como estatística, como banco de dados genéticos, informacionais, de consumo ou categoria de interesse [e por isso transformados] em algoritmos, equações, gráficos". (PELBART, 2013, p. 124). É essa força do capitalismo contemporâneo de usar máquinas e transformar os indivíduos em signos que em nada lembram o humano que envolve o inconsciente e causa a sensação de nada, de ausência de significado.

Os seres humanos nesse contexto têm recebido diversos nomes pelos pesquisadores das conformações pós-humanistas. Oliveira (2003) desenvolveu a ideia de que estamos vivenciando um devir ciborgue. Essa palavra de origem anglo-saxônica cyborg (abreviatura de cybernetic organism), para ela "significa que, hoje, o modo como construímos nossa subjetividade, nossa experiência no mundo, é intimamente relacionado à tecnologia. Tradicionalmente, o conceito de humano é construído a partir de sua diferença com a alteridade." (OLIVEIRA, 2003, p. 192). Após essa definição, a autora sintetiza: “As definições de ciborgue mais recentes incluem todo tipo de intervenção tecnológica, seja o uso de medicamentos (restauradores da saúde, psicotrópicos ou preventivos contra doenças), seja a conexão com instrumentos de mecânica, eletrônica ou informática.” (OLIVEIRA, 2003, p. $193)^{5}$

\section{O corpo literário em tempos de globalização}

No âmbito da literatura, a discussão que apresentamos acima sobre os processos de modernização e de vínculo entre o humano e a tecnologia, a dessubjetivação por meio do controle do corpo individual e social evoca a possibilidade de resgatar um gênero considerado menor durante muito tempo: a ficção científica.

A capacidade da literatura de absorver as modificações sociais e representar as conformações de uma maneira crítica é o ponto que se pode relacionar aos romances criadores de mundos imaginários ambientados em um futuro distante repleto de máquinas maravilhosas e perigosas. A tarefa que nos colocamos é analisar como a linguagem apropria-se desses

\footnotetext{
${ }^{5}$ Essa definição do ciborgue também aparece em Pelbart (2013), quando ele apresenta as ideias da psicanalista argentina Beatriz Preciado. O filósofo destaca que "o êxito da ciência estaria em transformar a depressão em Prozac, a masculinidade em testosterona, a ereção em Viagra etc.” (PELBART, 2013, p. 127).
} 
avanços, uma vez que o gênero ficção científica, em geral, trata da tecnologia mais em nível de conteúdo.

Com efeito, neste momento adentramos na produção literária contemporânea brasileira a fim de verificar como se articulam todas os problemas que expusemos anteriormente. Apesar de nossa interpretação organizar-se a partir de Favelost, de Fausto Fawcett (2012), apontaremos vez por outra outros romances. Para a análise, partimos do pressuposto de que a literatura também é um corpo e, em um contexto histórico-social em que se apela tanto para esse objeto, ela também sofre os apelos e as interferências sofridas pelo corpo humano.

O devir ciborgue, apontado por Oliveira sobre o ser humano, manifesta-se de uma maneira peculiar em uma literatura denominada "eletrônica", por Katherine Hayles (2009). Sustentada e construída por recursos midiáticos diversos, nos quais se destacam o uso da internet, as formas atuais de literatura merecem estudos mais profundos, auxiliados pelas teorias de comunicação, principalmente. Porém, nosso propósito é analisar a conformação de uma literatura "tradicional", isto é, publicada em papel, distribuída por uma editora e comercializada por uma livraria e que é lida com o papel em mãos.

Favelost, de Fausto Fawcett, é um romance em que se mesclam as características formais desse gênero. Ao mesmo tempo, a temática evoca constantemente uma semelhança com as obras de ficção científica. A "cientificidade" poderia estar localizada no conflito central do romance: os dois personagens principais, Eminência Paula e Júpiter Alighieri trocam mensagens pelo Twitter enquanto se procuram para que possam desativar um chip inserido em seus corpos. Por meio de uma "trepada" eles poderão desativar o microorganismo estranho. Eles se buscam pela Mancha Urbana Favelost, uma conurbação de dimensões gigantescas entre São Paulo e Rio de Janeiro. O controle dos de todos os habitantes por Torres Cartesianas é a principal característica dessa conformação urbana.

O ambiente descrito por Fawcett certamente não é realista. Favelost lembra em quase tudo a descrição de uma narrativa de ficção científica. Porém, o clima de futuro tampouco está descrito de uma maneira que lance o leitor em um outro tempo. Pelo contrário, muitas cenas e pequenas tramas parecem se desenvolver no entrecruzar de uma linguagem realista e de ficção científica em um cenário brasileiro bem atual.

Embora nossa intenção não recaia na tentativa de adequar o livro de Fawcett em um ou outro gênero, o resgate de algumas ideias poderá ser útil para a melhor compreensão do 
livro no que ele carrega dos tempos correntes e no que persiste de uma "tradição" da literatura brasileira.

Em trabalho que analisa algumas produções de ficção científica na América Latina, mas centrada quase que exclusivamente no Brasil, Elizabeth M. Ginway (2007) mostra que, apesar de sua forte ligação com um gênero associado com o Primeiro Mundo, na América Latina esses textos refletem as condições sociais e políticas dos países da região. Em outras palavras, ela defende que as conformações desse gênero em um país em que não há um histórico abundante de investimento em ciência e tecnologia apresentam temáticas cuja tensão oscila entre uma certa "futuridade" ${ }^{\text {e }}$ um certo "empenho". ${ }^{7}$ A partir disso, a autora analisa o corpo social brasileiro como uma região fronteiriça entre a "integridade da identidade nacional e a invasão tecnológica e informática da globalização.” (GINWAY, 2007, p. 788). Nos contos analisados e outros mencionados ${ }^{8}$ as personagens têm o corpo marcado pela opressão do poder político. A conclusão a autora é que "ao contextualizar os seis textos brasileiros de ficção científica do presente estudo dentro da época da economia global, vemos o tratamento do corpo como sintoma da crise do contrato social entre o povo e seu governo." (GINWAY, 2007, p. 788).

A tese de Ginway (2007) auxilia na compreensão de Favelost, na medida em que no romance abundam exemplos de opressão e exercício desse biopoder. Seja o pavilhão de negociação imobiliária descrito logo no primeiro capítulo seja nas Torres Cartesianas, metáforas dos atuais data center, a missão heroica de Júpiter Alighieri e Eminência Paula é oriunda de opressão a seu corpo. Por isso, vemos que essa metáfora do poder opressor, do exercício do biopoder levado ao extremo (a implantação de um chip) contra a vontade do indivíduo é a mais alta expressão dentro da narrativa.

Chama atenção dentro desse cenário ainda a "personagem" Intensidade Vital, uma "firma internacional de supletivo vital” para quem Júpiter trabalha e é encarregado de recolher uma "rapaziada misantropa" para oferecer "serviços de agulhação do ego" (FAWCETT, 2012, p. 13). Entendemos que essa empresa representa as atuais firmas de criação de aplicativos e redes sociais que, sob a ideologia de conectar todo o mundo e criar redes de sociabilidade, conquistam um grande percentual de jovens que oscilam entre os polos da solidão do

\footnotetext{
${ }^{6}$ A expressão não aparece no artigo de Ginway. Uso a expressão por conta própria uma vez que "futurismo" carrega já há quase um século a marca das vanguardas.

${ }^{7}$ Seguindo as lições de Antonio Candido em Formação da literatura brasileira, utilizamos "empenho" em lugar do galicismo engajamento. Nos contos analisados por Ginway, duas atitudes evidenciam a postura combativa: a postura contestatória contra o poder estabelecido e a violência do crime organizado.

${ }^{8}$ Um dos contos mencionados é "Santa Clara Poltergeist", de 1991, escrito por Fawcett.
} 
computador e a realidade virtual ou vivem experiências extremas de vida por meio do uso do álcool e de drogas.

A submissão ao poder das empresas de capital informacional, dessa forma, representa a expressão niilista e o esgotamento da vida. Essas situações são agravadas pela forma das cidades. Em Favelost, "as indústrias e mini-indústrias de manipulação atômica da matéria são presença chula na paisagem de arquiteturas desencontradas, superpostas e labirínticas" (FAWCETT, 2013, p. 15) 9 . Manipular a matéria, nesse contexto, é algo mais desolador do que o controle capitalista dos meios de produção e do trabalho. Entendemos que a manipulação da matéria é uma expressão do esvaziamento dos significados do trabalho e da própria vida, atitude muito semelhante ao que o estágio avançado do capitalismo conquistou com a engenharia genética e a nanotecnologia.

Restringindo nosso olhar ao caso brasileiro, cremos que as particularidades devam ser apontadas. A última década proporcionou avanço econômico, com distribuição de renda, e ampliação de sistemas educativos, aspectos importantes nos processos modernizadores. Porém, uma particularidade foi a possibilidade de conquista de bens materiais pelas pessoas de menor poder aquisitivo: desde televisores a viagens de avião para turismo, passando por carros.

A postura contestatória do romance está dirigida a essas conformações socioeconômicas tanto em nível global quanto às peculiaridades brasileiras. Essa postura contestatória provoca, ao longo da narrativa, momentos de reflexão ensaística ou uma verborragia que beira o lugar comum. Um exemplo é o capítulo 6 , em que o cenário de futuridade é praticamente abandonado e o narrador dispara críticas ao mundo e à configuração do capitalismo, na tentativa de compreender as mudanças desse novo milênio. No início, lemos:

a verdade é que depois de várias crises econômicas mundiais; depois da tentativa de
levar o assim chamado livre-mercado pela utopia neoliberal de teor religioso bem
messiânico; depois do $11 / 09$, principalmente aos países focos do terrorismo. De
Reagan a Bush. Depois dos Estados Frankensteins gerados pela globalização, sendo
a China o melhor e mais grandioso exemplo. Depois das heranças das Revoluções
Inglesa, Americana e Francesa; das tentativas modernizantes de se criar um novo
homem via comunismo totalitário ou nazismo; depois de todos os liberalismos,
anarquismos, monarquismos e absolutismos, era preciso um noto tipo de franquia
social que desse conta da efervescência da atualidade onde a mão quase invisível do
mercado coloca suas mãos em cima da mão, às vezes pequena e sutil, às vezes

\footnotetext{
${ }^{9}$ Reportagem da revista Veja de janeiro de 2014 demonstra os planos de grandes empresas de infocapital, tais como Google, Facebook e Twitter, em termos de arquitetura em cidades grandes e pequenas. De acordo com a reportagem, essa seria a principal estratégia para atrair jovens talentos. Essa estratégia ganha maior significância quando recordamos que as manifestações pós-modernistas ocorreram justamente na arquitetura (JAMESON, 2004; HAVEY, 2003).
}

Anu. Lit., Florianópolis, v. 20, n. 1, p. 246-264, 2015. ISSNe 2175-7917 
escancaradamente pesada, do Estado, e ambas são cobertas pelas patas cabeludas das hienas mafiosas, dos submundos, dos comércios movediços. (FAWCETT, 2012, p. 21).

O trecho narra rapidamente a evolução do poder na história da humanidade e as mais diferentes formas de governo que o sustentaram. Quase no final do capítulo, o narrador apresenta de maneira sintética o estado atual do mundo:

\begin{abstract}
A mistura acelerada dos três níveis de cultura: o canônico humanista baseado em leituras e formador de todos nós em termos de emancipação, domesticação do ser humano. O das velhas culturas desplugadas e oraloides, base de mentalidades étnicas e dos folclores. E o hiperurbano eletrificado, publicitário, massificado, eletronizado, digitalizado, enfim, plugado, apenas corroborou o que sempre existiu de forma mais lenta, mais refém do tempo - o nomadismo de tudo no que diz respeito às manifestações culturais. (FAWCETT, 2012, p. 22).
\end{abstract}

A imagem da mão que é capaz de controlar, invisivelmente como mágica, as relações humanas unida à síntese dos "níveis" de cultura nos dois trechos acima destaca a formação do mundo contemporâneo de base maquínica. A forma ensaística dada aos trechos encontra semelhança com a análise que Peter Pál Pelbart faz do uso do poder pelo capitalismo; uso que gera a sensação de niilismo:

\begin{abstract}
As tecnologias do feitiço no capitalismo contemporâneo se incrementaram muito, seja através dos dispositivos bioinformáticos de captura das almas e dos corpos, da mobilização integral da energia vital, da autorresponsabilização, do regime de 'controle do engajamento', e essa lista é extensíssima. Mas isso não se dá de maneira cega, pois passa por milhões de 'mãozinhas' que lhe garantem a eficácia, com diferentes graus de adesão, mantendo 'conjugadas' uma infinidade de conexões, leis, regulamentos, definições, modos de pensar. (PELBART, 2013, p. 125).
\end{abstract}

Percebemos pelas palavras de Pelbart que o controle, apesar de estar invisível aos olhos, é exercido por muitas pessoas, que estão incumbidas de criar e controlar os dados, as informações, as estatísticas em que se transformaram os indivíduos da sociedade no estágio computacional do capitalismo. Em Favelost, essa visão, em cujo nível discursivo as citações anteriores demonstram haver uma objetividade bem ao gosto do que se exige no mundo acadêmico em geral, está manifestada metaforicamente na tensão vivida pelos habitantes de Favelost e o Capataz de Humanista Júpiter Alighieri. Essa tentativa de abarcar os mais diversos problemas da sociedade e criar uma representação do contexto histórico aproxima Favelost tanto de uma abordagem realista quanto da ficção científica.

Porém, o romance de Fawcett não pode ser considerado de ficção científica, pois ele não traz mundos ex-óticos, realidades paralelas. Fawcett hiper-imagina uma realidade já 
existente, mas não da forma como está no livro. Os seres humanos não são autômatos ${ }^{10}$ ou ciborgues. São humanos com chip e conectados ao computador o tempo todo, não passaram por experiências científicas capazes de modificar-lhes a genética. A discussão é entre a realidade e a ética dessa realidade, problemática bastante presente nos romances realistas. Decorre daí, aliás, a carga exagerada de reflexões sobre a sociedade brasileira. Em Favelost não são os ciborgues que se transformam em humanos; são os humanos que estão, por assim dizer, ciborguizados. É o pós-humano.

Esse humano descrito em Favelost, embora seja constituído de uma historicidade (no capítulo 15, por exemplo, Júpiter Alighieri conta sua história), representa as transformações aceleradas temos a que temos assistido nas duas últimas décadas sobretudo. Para compreender tais transformações e esse pós-humano ou o devir ciborgue, podemos partir das ideias que Lúcia Santaella vem desenvolvendo. Em artigo de 2007 na Revista USP, ao falar da condição pós-humana, ela cita o livro Post-human Bodies, de Halberstam \& Livingston (1995) para explicar que "a história, concebida como história social e cronológica, está morrendo junto com o homem branco da metafísica ocidental. Por isso mesmo, os corpos pós-humanos não pertencem à história linear. São do passado e do futuro vividos como crise." (SANTAELLA, 2007, p. 132).

É nesse sentido que fica mais evidente a luta travada pelos habitantes de Favelost, embora apenas algumas pareçam ter consciência da transformação sofrida. A empresa Intensidade Vital e seu Capataz de Humanistas, cujo trabalho é recrutar "uma rapaziada misantropa" para viver experiências humanas intensas como "doenças terríveis e aprendizados tecnológicos" é uma ampliação das diversas facetas de nossa sociedade, dentre as quais se destacam os reality shows, as experiências de novos medicamentos e o apelo ao corpo como elemento da publicidade.

\section{A literatura niilista de Favelost}

De toda a problemática que emerge dos temas tratados em Favelost, outra reflexão importante a que o livro de Fausto Fawcett convoca é acerca de um possível ressurgimento do romance, esse gênero híbrido e modelante. Expressamos aqui um ressurgimento porque a narrativa recoloca o enredo ficcional com profundidade no centro do discurso romanesco, neste começo de milênio, em que a literatura brasileira parece ter optado pela narrativa curta e a concisão da linguagem, manifestada tanto em contos quanto em micro-narrativas.

${ }^{10}$ Para Oliveira (2003, p. 184), os autômatos são "engenhos mecânicos capazes de gerar seu próprio movimento". Nesse sentido, seria um nome ampla para designar as invenções tecnológicas. 
Para melhor compreensão do fenômeno romance no Brasil contemporâneo queríamos partir de um artigo publicado no final da primeira década do novo milênio. Em 2011, a crítica Walnice Nogueira Galvão foi convidada pelo jornal O Estado de S. Paulo para fazer uma análise da literatura brasileira. Em sua apresentação, três pontos nos parecem importantes.

O primeiro é a relação do escritor com o mercado. A autora destaca a imposição definitiva do mercado sobre a criação, em que há a especialização na produção de best-seller. Ainda nesse tópico, ela aponta que a publicação digital por meio de blogs, boletins eletrônicos e outras páginas diversas dispensaram a mediação de editoras. Portanto, dois caminhos que envolvem o mercado parecem ter se confirmado. Por um lado, uma literatura que deve atender a um público, ou seja, que precisa tornar-se comercializável e, por outro, uma suposta autonomia da arte, o que conseguiria gerar experimentações da linguagem ${ }^{11}$.

Do ponto de vista temático, Galvão afirma que a literatura brasileira tornou-se definitivamente urbana. Essa temática está conformada pelo thriller, que, segundo a autora, é marcado pela ação violenta cheia de suspense. Nesse formato, "tendendo ao despojamento, trouxe tanto o desprezo pela retórica quanto a vontade de depuração [...], encolheu o léxico [...] e a gama de assuntos." ${ }^{\prime 2}$.

Por fim, existiria também uma linhagem pós-modernista, em que a narrativa convencional é colocada em xeque por meio de estilhaços, manejo da intertextualidade ${ }^{13}$, colagem, montagem e a desconstrução.

Favelost afasta-se das três tendências que destacamos e das demais que omitimos, como a revitalização do regionalismo. Quando aproximada dos autores citados por Galvão em cada uma das tendências, encontramos dificuldades devido à brevidade de suas reflexões e, sobretudo, porque ela faz um levantamento de autores que podem ser consideradas consagrados e com uma trajetória. Em movimento oposto, preferimos trazer para a discussão algumas obras, escolhidas aleatoriamente, que tratam de questões semelhantes às de Favelost e que também são narrativas.

\footnotetext{
${ }^{11}$ Sobre a questão da autonomização da arte a partir de um problema, ou seja, a dominação mercadológica e os meios técnicos de reprodução, gostaríamos de sinalizar o livro Desencontros da modernidade na América Latina, do argentino Julio Ramos. O autor demonstrar a forma como o jornal, na Buenos Aires do século 19 criou um duplo movimento: ao mesmo tempo em que massificava a produção literária e dificultava a criação de uma escrita cultivada e trabalhosa, abria caminho para as transformações da linguagem literária e era responsável pela projeção do escritor na sociedade.

${ }_{12}$ Ainda sobre as várias formas de publicação, é preciso destacar aquelas que são oriundas da compilação de textos esparsos previamente publicadas em blogs.

13 Jameson aponta, por outro lado, que a intertextualidade não é uma marca da pós-modernidade. O procedimento, na verdade, já estaria modificado.
} 
Acerca da proximidade entre a conformação das grandes cidades e a vida maquínica, podemos destacar O fluxo silencioso das máquinas, de Bruno Zeni (2002). O livro, que não traz indicação de gênero, apresenta 105 narrativas cuja principal característica é a descrição nominal de espaços urbanos. A presença das máquinas, referência à conformação social de uma metrópole como São Paulo, não sofre uma simbiose com a linguagem literária, ou seja, não há absorção dos conteúdos contemporâneos pela linguagem literária. Parece que há em verdade um distanciamento entre a subjetivação de uma voz narrativa e o cenário mostrado. As narrativas, todas muito curtas, reproduzem algumas tensões típicas de uma visão marxista, ainda que esteja esboçado o problema da conformação das metrópoles e a opressão capitalista.

Da mesma forma, Eles eram muitos cavalos, de Luiz Ruffato (2001), mesmo mantendo uma linha narrativa ficcional cuja marca é a profusão de vozes e de gêneros discursivos (hagiografias, notícias, lista de livros etc.) a temática da opressão social das camadas mais desvalidas é ainda tratada sobre a velha dicotomia marxista.

Nas duas obras citadas (certamente universo muitíssimo restrito para tentar desenvolver uma ideia mais abrangente do fenômeno romanesco no Brasil), o destaque fica por conta da condensação da linguagem e daquilo que constituiu, segundo Antonio Candido, a literatura brasileira: o empenho. Tanto no romance de Bruno Zeni quanto no de Luiz Ruffato a linguagem apresenta-se muito condensada. Poderíamos dizer que há quase um desaparecimento da palavra.

Esse procedimento, que foi expediente muito utilizado nas vanguardas e pelo nosso Modernismo, porém, não acontece em Favelost. Os procedimentos de linguagem utilizados são variados, certamente, dentre os quais: fina ironia e um acentuado sarcasmo, criação de neologismos, repetição, às vezes enfadonha, dos mesmos termos e mesmas ideias, mistura de elementos da chamada alta cultura com a cultura de massa e, para fechar, jogos de palavras.

No nível estrutural permanece a narração, mas ela não é linear nem cronológica. Em diversos momentos, na verdade, o fluxo narrativo é suspendido para reflexões sobre o Brasil contemporâneo. Esse procedimento dá um caráter ensaístico ao texto e, não raro, a linguagem perde expressividade porque cai em estruturas sintáticas típicas da maçante escrita acadêmica. Um dos momentos em que a expressividade verborrágica do discurso de Favelost explode e demonstra uma profusão variada de registros acontece no capítulo 7 , no qual não há uma sequência da trama, apenas uma reflexão sobre o Brasil contemporâneo, apesar de simular a "futuridade" do tempo da narrativa. Já no final, lemos o seguinte: 
[O Brasil é] Paiol de vertigens e desequilíbrios que nunca fodem o país, nunca o jogam na bancarrota graças às ilhas de competência, é claro, mas também nunca o deixam deslanchar de acordo com algum receituário de mercado, de organização política, judiciária, legislativa, executiva decente. [...] Apesar de todas as forças do atraso, o flerte do país com o progresso é inegável nos últimos sessenta anos (industrialização, programações sociais, constituição, democratização, investimentos em educação, saúde, etc.), mas também é inegável que falta muito pra se alcançar alguma massificação desse progresso em virtude da corrupção, da incompetência, politicagens mafiosas ou não mafiosas, desleixo interesseiro, restos de autoritarismos coronelistas e capitanias hereditárias camufladas nas leis, falta de prioridade para projetos educacionais, científicos e tecnológicos, falta de reformas jurídicas, políticas e fiscais, falta de capitalismo e modernidade. (FAWCETT, 2012, p. 28).

No trecho acima, é explícito o lugar comum sobre o Brasil e, inclusive, há uma simplificação da linguagem, a qual é evidenciada pelas relações entre estruturas sintáticas típicas do discurso acadêmico: “apesar de [...] é inegável [...] mas também é inegável”. Por outro lado, é nos momentos de sarcasmo e condução da narrativa que a linguagem é enriquecida. É o que acontece no capítulo 11, quando aponta quatro empresas que se destacam em Favelost: "a Nanocréu, avançadíssima nas pesquisas de velocidade de transmutação molecular [...]. Departamento de velocidade um, dois, três, quatro e cinco [...] No ramo da genética, a Bio-Ser é a que comanda e faz muito sucesso com seu sloganmandamento: 'Por uma humanidade gostosona'.” (FAWCETT, 2012, p. 39).

A “dança créu”, um dos símbolos da massificação musical, está conjuga com uma possível nanotecnologia. A outra empresa citada, provavelmente um trocadilho com o nome da cantora Beyoncé, representa uma das principais formas de exercício do biopoder na era do infocapitalismo, em que a mídia dirigida ao corpo impõe padrões não apenas de pensamento e das ideologias, mas também de constituição física do ser.

Esses recursos de linguagem, que poderiam ter mais exemplos, gera uma sensação de paralisia durante o romance. Em outras palavras, a linguagem de Favelost oscila entre a acumulação estática e o movimento. A acumulação, que poderia causar um efeito de esgotamento da palavra por causa da contensão do fluxo narrativo, é aprimorada no plano lexical pelos muitos neologismos que surgem após um número acentuado de imagens e ideias. Exemplos desses momentos são as expressões: “a reza vou-me-dar-bem” (p. 8); "resto-deaçúcar-fica-quieto" (p. 9); "amoródio" (p. 10); “enerdizados" (p. 14); "Rio Paulo de Janeiro São" (ao longo de todo o livro) e "esquerdofrênicos" (p. 31). Eles funcionam como síntese, como categorias que devem ser criadas para nomear novos fenômenos e objetos.

A questão da linguagem que vai até o limite foi também algo relevante em um dos romances mais comentados na literatura contemporânea brasileira. Referimo-nos ao romance As visitas que hoje estamos, de Antonio Geraldo Figueiredo Ferreira (2013). A temática da 
tecnologia está bem distante do universo criado por Fawcett ${ }^{14}$. Romance em que desaparece a voz narrativa única, a cronologia e a linearidade, e que em muitos momentos parece ser uma série de micro-narrativas cujos enredos tratam de temas universais (o amor, a solidão, a velhice, a amizade etc.) em uma perspectiva contemporânea. Daí a violência real das cidades grandes (e pequenas) e sua espetacularização dos programas de tv, bem como a religiosidade ora irônica (como o capítulo “?”, em que há existe a imagem de um "Capela dos santos anônimos" acompanhada da reflexão “meu deus, pra quem eu vou rezar agora?”) ou crítica, quando trata da presença evangélica no cotidiano e o uso do velho recurso de criticar o enriquecimento desse seguimento religioso.

Mesmo não sendo o foco, uma das narrativas é "www". Nela o aspecto religioso, marca central já anunciada na capa, se entremescla ao uso banalizado e esvaziado da linguagem corrente dos e-mails e gêneros semelhantes:

adorei presente, q escapulário lindo, vc me conhece, da moda, $\mathrm{d}+$, igual arte, quem naum entende mto acha comum, acha feio, ou naum acha nada, naum sou religiosa mas estou usando, acredito em deus de vez em quando, bjs (FERREIRA, 2013, p. $80)$.

Voltando à questão de ir ao limite da linguagem, o que se vê no romance é uma tentativa de resgate da oralidade. Por isso, o enriquecimento cultural e linguístico em épocas de literatura que perdeu a linguagem como matéria-prima. Essa característica de Favelost e de As visitas que hoje estamos (em um, o neologismo; em outro uma sintaxe agramatical) é tão marcante que a crítica jornalística comparou os romances à linguagem de Guimarães Rosa. Certamente, Antonio Geraldo está mais próximo do autor de Corpo de baile devido à religiosidade e à oralidade e, por que não?, à mineiridade. Mas o que ele parece trazer para a literatura contemporânea é mais do uma tradição da típica tensão entre urbano e rural. $\mathrm{O}$ estranhamento maior é o de Fausto Fawcett, cujo universo urbano e futurístico do romance evocam um ambiente muito distante de Rosa ${ }^{15}$.

$\mathrm{Na}$ verdade, o que aproxima os contemporâneos de um dos maiores clássicos da tradição brasileira é a exploração da linguagem em vez da escrita de uma narrativa referencial.

Essa projeção de signos, promovida mais amplamente por Fausto Fawcett, metaforiza um tempo em que a profusão de sinais, principalmente dirigidos ao controle, à disciplina, à modelagem do corpo, promovendo o que se poderia chamar de pós-humano,

${ }^{14}$ Talvez o recurso que mais se aproxime de um uso "tecnológico", isto é, recurso que incorpora a tecnologia como tema ou conteúdo, seja o uso de imagens responsáveis por construir a narrativa juntamente com o texto verbal. Não se trata de ilustrações, mas campos de interpretação que ampliam o significado da linguagem literária.

${ }^{15} \mathrm{Cf}$. o colunista do jornal $O$ Globo Hermano Vianna, em http://oglobo.globo.com/cultura/favelost-6374573. 
parece ser a representação niilista da literatura contemporânea, desde que esse niilismo seja entendido como foi explorado por Pelbart (2013, p. 93):

\begin{abstract}
O niilismo em Nietzsche tem um caráter sabidamente equívoco. Por um lado, ele é sintoma de decadência e aversão pela existência, por outro, e ao mesmo tempo, é expressão de um aumento de força, condição para um novo começo, até mesmo uma promessa. [...] Não me parece absurda a hipótese de que parte do intersse que ainda desperta o arauto da transvaloração se deva a esse traço tão contemporâneo de seu pensamento, no qual o declínio e a ascensão, o colapso e a emergência, o fim e o começo coexistem em um embate irresoluto.
\end{abstract}

Nietzsche acreditava estar falando daquilo que viria. Viver a experiência niilista não seria, pois, esconder-se em uma subjetivação, promover um "grau zero de subjetivação", mas viver um "extremo de intensificação". (PELBART, 2013, p. 71). O romance Favelost parece, ao marcar o corpo de sua linguagem com uma profusão de signos oriundos das nomenclaturas que designam os objetos criados pelo mundo contemporâneo, promover esse extremo de intensificação e anunciar "aquilo que vem" em termos de literatura — talvez por isso não seja aleatória a presença constante do advérbio "agora" em inúmeras páginas do livro: Favelost é a "futuridade" do Brasil: "Enquanto o Brasil se preocupava com corrupções, balanços econômicos, estatísticas, epidemias advindas das insalubridades, Favelost acontecia". (FAWCETT, 2012, p. 40). Essa intensidade extrema é o trabalho de Júpiter Alighieri e Eminência Paula: oferecer mais vida.

Em oposição à intensidade de vida provocada pelas máquinas, em oposição ao trabalho dos protagonistas, Favelost pode ser vista como algo que já vem acontecendo. Promessas de vida e futuro melhores mediados pelas tecnologias, próteses, chips e outras máquinas estão em oposição à ontologia existencial do homem. Contudo, é nesse momento que o livro de Fawcett parece potencializar uma esperança. Nos capítulos 14 e 27, os capatazes de humanistas Júpiter Alighieri e Eminência Paula, assassinam um imigrante mexicano e uma idosa respectivamente. A morte acontece porque nenhum dos dois aguenta mais a materialidade do mundo em que vivem. A idosa, por exemplo, conseguiu prolongar a vida com a ajuda de inúmeras drogas e próteses. A execução é feita por um instrumento, por corpo estranho àquele mundo: uma caneta tinteiro. A imagem do assassinato, pelos capatazes de humanistas, por meio de uma caneta - metáfora clara da escrita e do escritor - mostra que a intensidade de que a contemporaneidade precisa é ainda do humano e que a literatura é um caminho para essa revitalização.

\title{
Considerações finais
}


A breve análise que realizamos de Favelost e da narrativa brasileira contemporânea sob a perspectiva das reflexões sobre o corpo percebemos que esse romance parece promover uma revitalização da arte de narrar e da linguagem. Para Jameson (2004), uma das marcas do pós-modernismo seria o desaparecimento das narrativas totalizantes, uma vez que na pósmodernidade teria havido a perda das grandes ideologias e das crenças em profundas mudanças. Favelost, porém, ao manter uma "tradição" da literatura brasileira, a saber, a postura de empenho e incursionar por uma "tradição" de literatura de primeiro mundo, a ficção científica, resgata uma totalização do discurso artístico-literário.

Apesar de manter uma postura questionadora e receosa dos avanços tecnológicos, o romance propõe uma saída. Se considerarmos que a literatura é um corpo e que estamos vivendo um estágio avançado da tentativa do ser humano de ultrapassar os limites de seu corpo (SANTAELLA, 2007), identificamos que a postura combativa encontra um caminho profícuo ao usar as "armas" de combate. Fausto Fawcett, em lugar de usar uma linguagem linear e tradicional do romance, registra no corpo do texto as marcas de seu tempo. Um exemplo é o uso do léxico da própria tecnologia e a invenção de novo léxico: trata-se da profusão de signos, elemento justamente constituinte do humano e do literário.

\section{Referências}

BERADI, Franco. After the Future. Edinburgh, Oakland, Baltimore: AK Press, 2011.

FAWCETT, Fausto. Favelost: (the book). São Paulo: Martins Fontes, 2012.

FERREIRA, Antonio Geraldo. As visitas que hoje estamos. São Paulo: Iluminuras, 2013.

GALVÃO, Walnice Nogueira. A produção nacional vista em perspectiva. O Estado de S. Paulo, 13 ago. 2011. Disponível em: http://cultura.estadao.com.br/noticias/geral,a-producaonacional-vista-em-perspectiva-imp-,757956. Acesso em: 07 jul. 2014.

GINWAY, M. Elizabeth. Do implantado ao ciborgue: o corpo social na ficção científica brasileira. Revista Iberoamericana, v. LXXIII, n. 221, p. 787-799, out.-dez., 2007

HAYLES, Katherine. Literatura eletrônica: novos horizontes para o literário. Rio de Janeiro: Global, 2009.

HAVEY, David. Condição pós-moderna: uma pesquisa sobre as origens da mudança cultural. 12.ed. São Paulo: Loyola, 2003.

JAMESON, Fredric. Pós-modernismo: a lógica cultural do capitalismo tardio. 2.ed. Trad. Maria Elisa Cevasco. São Paulo: Ática, 2004.

OLIVEIRA, Fátima Regis de. Ficção científica: uma narrativa da subjetividade homemmáquina. Contracampo, n. 9, p. 177-198, 2003. 
PELBART, Peter Pál. O avesso do niilismo: cartografias do esgotamento. São Paulo: N-1, 2013.

RUFFATO, Luiz. Eles eram muitos cavalos. São Paulo: Boitempo, 2001.

SANTAELLA, Lúcia. Pós-humano - por quê? Revista USP, São Paulo, n.74, p. 126-137, jun.-ago. 2007.

ZENI, Bruno. O fluxo silencioso das máquinas: pequenas iluminações asfálticas. Cotia: Ateliê, 2002.

[Recebido em janeiro de 2015 e aceito para publicação em maio de 2015]

\section{A global literature: the body of literature in Fausto Fawcett's novel Favelost}

Abstract: The work discusses some aspects presented in Fausto Fawcett's novel Favelost. The narrative has similar elements of the ciberfiction and its main aspect is the use of linguistic resources such as neologism, irony, pun, etc. Therefore, the exploration of language became literacy language revitalization without the focus in a social perspective, which has been one of the main feature of the contemporary Brazilian literature. With the readings of nihilism that were made by Pelbart (2013), the profusion of signs that inscribe in the body of narrative could be a sample of the redemption of human being and the literature through symbolic representation.

Keywords: Contemporary Brazilian literature. Innovation and tradition. Posthuman. Nihilism.

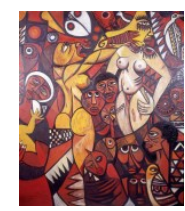

